\title{
Is Crisis the Only Way to Put Innovators in Charge in Hierarchical Firm?
}

\author{
Evgeny Torkanovskiy ${ }^{1 *}$ \\ ${ }^{1}$ Russian Academy of Sciences, Moscow, Russia \\ *Corresponding author: Evgeny Torkanovskiy: torkanovsky@gmail.com
}

Citation: Torkanovskiy E. (2019) Is Crisis the Only Way to Put Innovators in Charge in Hierarchical Firm?. Open Science Journal 4(1)

Received: $18^{\text {th }}$ March 2019

Accepted: $8^{\text {th }}$ May 2019

Published: $23^{\text {rd }}$ May 2019

Copyright: () 2019 This is an open access article under the terms of the Creative Commons

Attribution License, which permits unrestricted use, distribution, and reproduction in any medium, provided the original author and source are credited.

Funding: The author(s) received no specific funding for this work

Competing Interests: The author have declared that no competing interests exists.

\section{Abstract:}

The way innovators are recruited and treated within organization impacts the company's ability to innovate. Based on literature review this research finds evidence that contrary to Schumpeterian assumptions that large companies through concentration of resources play leading role in innovation process, big hierarchical firms may fail to innovate due to recruiting patterns. Corporate hierarchy, unlike markets, tends to maintain permanent and total control of the employees and to punish and push out the least controllable. The manager has personal interest to hire and promote the most controllable employees, the ones least threatening to the manager's status and not the most creative or innovative. This inherent feature of any hierarchy may make it unable to recruit, promote innovators and thus maintain efficient innovation process. It leads to accumulation of innovation errors and lags and to regular crises within hierarchy and of hierarchy itself due to the lack of progress and innovation. However, the crises may lead to management renewal and innovators' promotion to decisive positions and roles. On the other hand, it means that in order to adopt and implement innovations a hierarchy requires internal or external shocks, sometimes even self-generated or exaggerated.

Keywords: Hierarchy; Recruiting; Innovation; Controllability; Crisis 


\section{Innovation and corporations}

Modern firms consider innovation as one of the basic activities necessary to stand atop the competitors. The third and fourth industrial revolutions (Rifkin, 2011) and growing pace of innovations make the firms' management anxious to incorporate innovations and innovation management techniques to avoid the fate of their less successful peers. Innovation has become a major concept in both economics at large and economic analysis. Many experts believe that innovation has developed into the industrial religion of the late twentieth century. Numerous works largely emphasize the fundamental role of innovation as a determinant success factor on firm and industry level. However, recent trends in the literature focus on the question why new technological innovations are not always adopted and that older technologies are still in use, even though they compete with newer ones. Our research deals with this issue from the point of personnel selection and managerial alertness to innovation.

Innovation is one of the firm's economic activities that evokes general interest and is diligently pursued. Economic, social and technical progress is not possible without innovation. Innovation activity, according to Schumpeter (1942), is the result of purposeful actions of oligopolistic firms that have the necessary resources to carry out research. Schumpeter (1934) was the first to introduce the notion of economic development as creative destruction. In Schumpeter's view innovations represent the result of entrepreneurs' efforts, as entrepreneurs find in the existing pool of knowledge inventions that were not previously commercialized, and introduce these ideas-inventions into the economic life, thus creating innovations.

The three main conclusions stem from original Schumpeter's innovation theory.

1. Invention as an activity is an exogenous process for the economy, that is, inventions are privatized by entrepreneurs who know how to make money on inventions.

2. Technological innovations lead to economic development with the help of new products and processes that are introduced by entrepreneurs.

3. The innovation process is linear, beginning with the invention and ending with innovation, where profits emerge.

These three Schumpeterian ideas led to the conceptual framework of the linear model of innovation whereby exogenous technological innovation pushes economic growth. The supporters of this concept maintain that already by the middle of the 20th century inventions have become highly dependent on targeted research and technology development while a solitary genius inventor such as Edison or Tesla has become a mythological figure with the inventions being the result of purposeful and systematic research and development efforts. This led to the general scheme for the innovation process, that was widely accepted at corporate, national and international level: research leads to inventions that, in their turn, create opportunities for innovations, thus making economic growth possible.

Such a linear concept of innovation had serious political and economic consequences. Bush (1945) advocated the need for extensive state support for scientific research and development, using both general arguments (the desire to enlarge knowledge boundaries) and three pragmatic considerations - to stop 
diseases, ensure national security and provide economic growth. The more research expenditures increase, the more innovations will ensue, as argued by d'Este et al. (2012).

However, already in 1966 Schmookler (1966) questioned Schumpeter's linear model of innovations finding evidence that the upsurge in invention activity was a reaction to the growth in demand. This changed the direction of the causal relationship, which was implicit in the paradigm of exogenous technological change and demonstrated that endogenous forces of demand, acting from within the economy, are the cause of inventions and innovations. Later research confirmed that the process of innovation is much more complex than originally thought. In the mid-1980s a new concept proposed a radically new way of interpreting technological innovation. The main ideas were that technological changes are endogenous (rather than exogenous) for the economy, and innovation is a complex process in which companies, organizations and the state interact with each other (unlike the linear unidirectional model associated with increased demand or technological changes). A number of researchers hold the view that this approach to innovation corresponds to Schumpeter's later view, which he set out in his 1942 work, where he pointed out that innovation is more the result of targeted actions by oligopolistic firms that have the resources to carry out scientific research.

Studies and models of Kline-Rosenberg (1986), Freeman-Lundvall (1988), Chesbrough (2003) underscored the interdependence and interactions within the firm's innovation system and opened it to external institutions and environment as a whole. This understanding of innovation, while placing the company at the center of the innovation process, attaches great importance to the environment in which the firm operates. To achieve success in innovation, the environment is important. The emphasis shifted from linear logic, where innovation is a single phenomenon, to the philosophy of the socio-economic process that underlies the economically oriented technical novelty. Thus, the ability of social absorption of new technologies in the economy plays a central role. This absorption capacity is related to human capital, the institutional framework in which the national innovation system is built, the existing knowledge base (it may depend in part on basic research), previous training and experience in innovation and a number of other factors.

Traditionally the problem of internalization and externalization of economic activities within the organization is seen as a choice in the dichotomy of markets and hierarchy, with the markets associated with freedom and equality of the sides of the transaction, and the hierarchy with subordination and command relationships. This paradigm suggested by Coase $(1937,1960)$ and based on transaction costs analysis (Williamson (1985) with the subsequent division of the transaction costs in different categories allowed researchers (Malone et al. (1987), Clemons et al. (1993), Ciborra (1993), Rosa (2006), among others) to show that technological progress in information production and transmission leads to a shift of balance in this dichotomy in the direction of the markets and reduces the available space for hierarchy due to the contraction in the size of the organization and vertical hierarchy. In the same manner big data dramatically changes the very essence of the firm's boundaries making them easily penetrable both from inside and outside, as evidenced by Constantiou and Kallinikos (2015). 
Despite Schumpeter's view that large hierarchies may be the best option for innovations development Bower and Christensen (1995), Christensen (1997, 2003) showed that disruptive innovations do not originate within the firms-market leaders despite their best knowledge of their clients and technological sophistication. Industry or sector leaders often fail conceding the market to new, unexpected competitors. Gans (2016) has further nuanced the disruption concept identifying demand-side and supply-side disruption. The consequence of a new understanding of innovation is the desire for stronger integration of functions within the company. In particular, communication is a key factor while fundamental research is important, but hardly critical or even necessary for innovation, though coordination and integration of decision-making structures are necessary. The latest models of innovation and technology transfer underscore the importance of communication and the integration of functions and activities. This directly relates to the personnel selection and recruiting of innovators in large organizations.

Modern innovative activity can be divided into several types depending on its placement inside, on the border or outside the organization. The most popular is the paradigm of open innovation, which suggests that firms can and should use external innovation ideas in addition to internal developments, as well as use external and internal ways of bringing innovations to the market, as firms seek to advance their technologies. The boundaries between the firm and its environment have become much more permeable; innovations can easily be imported to or exported from the organization.

The basic idea of open innovation by Chesbrough (Ibid.) is that in a world of widespread knowledge, companies cannot afford to rely solely on their own research. Instead, they must purchase patents and licenses for the use of technology or inventions from other companies. In addition, internal inventions not used in the company's business should be used outside the company (for example, through licensing, joint ventures or spin-offs). In this concept large organization is neither the unique nor the best place to develop innovations. However, along with open innovations, there is also a paradigm of closed innovation (Dahlandera \& Gannb, 2010), which argues that successful innovation requires control. In particular, the company must control the generation of its own ideas, as well as production, marketing, distribution and sales, service and maintenance, financing and support.

Thus, there exists a full spectrum of opinions regarding large hierarchical organizations and their relationships with innovations and innovation activity and innovators. This paper maintains that innovation is primarily the function of creative force and spirit of humans, especially in view of current artificial intelligence ascension and robotics development. Bearers and developers of innovative ideas are people, though significant capital is often required to bring innovation into existence. So, the question of attracting and placing the right people in the right positions is the key to the development of innovation within the large organizations that are predominantly hierarchies. In this paper we intend to take further the research of the relationship between the hierarchy and innovation activity taking into account the recruiting and selection patterns within the organization and show that hierarchy itself limits the potential scope of innovation despite possible impact of technologies and information. Today, knowledge is no longer the property of the company. It is found with employees, 
suppliers, customers, competitors, research organizations, including universities. If companies do not use the knowledge that they developed internally, someone else can make use of it.

The paper is organized as follows. Next section presents a comparative overview of literature dealing with employee selection and recruiting in hierarchies and markets. This is followed by a description of a suggested model of employee recruiting within hierarchies depending on such properties of individual employee as creativity, controllability and qualification. We continue with a case study based on our model undertaken in traditional hierarchical organization. Guided by a literature review and preliminary observations, we collected data about the personnel selection processes through 24 semi-structured interviews in major hierarchical organization. These data were analyzed to develop explanatory themes. We subsequently move on to considering alternative ways to instill innovative spirit in the hierarchies described in literature and to discussing what are the model's implications for hierarchies and significant impact of employee selection process on crises of hierarchies. In conclusion we outline some possible further areas of model's application.

\section{Employee selection in markets and hierarchies}

The first known hierarchical structures were military, where submission and precise execution of commands were necessary for the success of both offensive and defensive operations. The superiority of the integrated command center processing information and taking decisions obligatory for all, and of the organization providing a clear and timely execution of commands, over a numerically superior but poorly organized enemy was demonstrated by Alexander the Great and Genghis Khan. When faced with the militia, formed on the basis of cooperation and unsettled and constantly changing relations both within the militias and between militia and the leaders, the professional hierarchical organization had clear advantages that have been successfully proved in battle (Coetzee and Eysturlid, 2013).

Hierarchy as an organizational innovation proved great success. However, its recruiting method, especially at lower levels (slaves, army and navy recruits) often caused unrest (Rogers 2008), as recruiting methods of a democracy (the market) and hierarchy are radically different.

Within the market or democracy an elector in his exercise of choice is guided by three main criteria: first, the confidence (compare with "trust", as put by Putnam (1993), or "trust capital" described by Breton and Wintrobe (1982)), that he feels for potential contractors or elected leader. Second, the complete information about the counterparty, his/her projects, information regarding actions in similar circumstances, the history of commitments taken and met and so forth. Third, qualification (competence for the job). However, after the selection is done there is virtually no possibility of control of the selected subject in the framework of democracy or of the market. The checks and balances system does not allow to do ultra absurd or self destroying things, but nothing prevents from not fulfilling the promises, from abandoning the policy promoted during the selection/election process or from ignoring the interests of the voters/clients. 
Unfortunately, the elector cannot punish the violator until the next elections. The control mechanism of the market has similar deferred action characteristics - a rejection of the transaction or refusal of delivery, which typically occurs due to non-compliance with the quality requirements or broken timing. Thus, the market mechanism of monitoring and sanctions is post-transactional in its nature.

Within the hierarchy, the selection of a new subordinate is happening on entirely different criteria. In conditions of command and subordination the control may be constant and continuous to provide a desired result. This is especially important at the initial stages of training, when the trainee is under constant supervision as the hierarchy needs to assess the trainee's skills, qualifications and attitudes quickly as well as to immerge the trainee in the specifics of the hierarchy's internal mechanisms and logic in order to make him/her function in accordance with its rules and customs. On the other hand, to complete the task especially related to innovation the new employee must possess certain qualifications and a certain degree of creativity, that is, the ability to create something new in order to achieve the desired result. Not every skilled task requires a high level of creativity. Baron, Hannan and Burton (1999) pointed out that executives of new technology companies distinguished as main factors for hiring an employee his/her attachment to the company, the possibility of coordination and control of the worker and the individual preferences of the executive in the formation of the team. Surprisingly (or not?), creativity or innovativeness was not included in the list.

\section{Model of employee selection in hierarchies}

In order to have more insightful analysis of the recruitment patterns within hierarchical organizations and better understand the possibility of creative individuals as bearers of innovation to ascend to the positions within hierarchy we have undertaken to develop a model that will allow us to consider the issues in depth.

For our purposes, to formalize the study of established (versus new) hierarchies in terms of recruitment, we suggest using a model in which each person $(\mathrm{Hi})$ has several major properties: creativity $(\mathrm{Ci})$, controllability, or dependence from control (Di) and qualifications (Qi). Thus, we may assume that

(1) $\mathrm{Hi}$ (Ci, Di, Qi)

From the point of view of fair play and the interests of business it seems logical that the firm should tend to hire a person who has $\mathrm{Hi}$ at maximum, which means that all three components should be maximized or $\mathrm{Ci}$ tends to max, Di tends to max and Qi tends to max. Some critics may note that creativity may be negatively related to controllability. Nevertheless, we assume that this relationship may not be empirically confirmed and does not have direct impact on our model. Interestingly, according to Wojtczuk-Turek and Turek (2015) employees' individual flexibility is generally a weak predictor of innovative behaviors.

In order to understand the model's workings let us consider the managerial recruiting decision in the hierarchy in the real world. Let's start with recruiting for typical (not specially creative or innovative) tasks performance. The 
manager's own goal in recruiting a new employee is to maximize his own utility and remuneration that is both monetary and non-pecuniary depending on the work system. However, non-pecuniary remuneration plays a leading role as the manager's primary interest is to maintain his/her place in the hierarchy and, if possible, to move to upper levels with corresponding increase of both material and immaterial perks. It's illogical for the manager to recruit an employee to slide down in hierarchy or quit. Thus, the manager is interested to hire an employee who would be able to carry out the task under the manager's control and in accordance with his/her requirements. Whatever the system of manager's appreciation and remuneration, be it KPI, balanced scorecards or plain sales/output, the two main issues for the manager is to have the work done and to have it credited to him/her. Both problems are successfully resolved by hiring the most controllable employee, not the most qualified or creative one. The most controllable candidate will do the work (subject to minimum qualifications needed) and will not revolt or try to own the results to the detriment of the manager. The constant control from the manager also means that he/she actively participates in the task so his/her performance results will be credited to the executive. It leads to hiring a team member/subordinate with the qualifications set at minimum required level, but the most controllable and dependent on the manager. Thus the manager secures his/her place in the hierarchy (no revolt) and provides that the work would be continuously done in accordance with his/her orders and schedule and under his/her control. The level of creativity does not matter much as we have initially stipulated that the work does not specifically demand this kind of skills. Furthermore, as empirical evidence shows, the less creative a person is, the faster and more efficiently he/she performs routine tasks that make more creative human bored or look for a way to do them outside the box, which also reduces the efficiency and increases the performance time of the operation, at least temporarily.

Thus, to maximize recruiting manager's returns, Di of successful job applicant should approach max, Qi should be fixed at the minimum required level, and $\mathrm{Ci}$ does not matter. As a result the manager selects a potential employee not from the whole pool of candidates but from a limited variety. Such managerial behavior also may give a boost to such a phenomenon as the appearance of overqualified unemployed who are unable to land a job in the hierarchy. The higher the qualification of the worker, the less he/she is easy to control, the bigger threat for the manager that he/she may be substituted by the newly employed. Thus, contrary to generally accepted idea and ideal world situations Hi function is optimized for $\mathrm{Di}$, and not for Qi or Ci.

So, if in the hierarchy selects an employee to perform a task that does not require creativity:

(2) $\mathrm{Ci}$ is variable

(3) Qi is fixed at minimum acceptable level.

(4) Di tends to max.

This may explain, on the one hand, the potential replacement of many employees in the hierarchy who perform typical, not creative tasks, by robots or artificial intelligence designed in accordance with the requirements of the management, and, on the other hand, the rapid development of technical means of performance control for employees in order to maximize Di, thereby reducing the number of supervisory staff. The disappearance of middle management is 
often considered as the result of positive managerial developments. However, it may often be the result of the growing technical complexity and not the organizational culture change. Thus, we see that from the possible employees' pool the hierarchy selects not the most qualified and experienced employee, but the most potentially controllable employee. In this connection it is interesting to note that when Marx wrote about specialization and transformation of the universal man of Renaissance into a man-function of capitalist production, he focused his interest and predicted worker's future evolution on worker's qualification as a key transformation driver, ignoring the fact that the personnel performance at capitalist enterprises analyzed by him was strictly controlled by capitalists (Marx, 1959).

In line with our model, Alchian and Demsetz (1972) underscore the monitor's incentive to reduce shirking of the team's members due to his/her residual claimant status. This also may induce the monitor to recruit team's members who are the most controllable as in this case the shirking of such employee may be efficiently controlled and reduced.

Our model may also partly explain the interest of the manager to re-train the existing employees who have already displayed the maximum level of controllability instead of hiring new qualified workforce from the market with uncertain or untested controllability characteristics.

To sum it up, the model has shown that relatively less creative tasks may form the management's demand for highly controllable/dependable workers whose qualifications may be limited and whose creativity is not an important factor. We understand that contemporary robots can be a good substitute for a worker with similar characteristics. Artificial intelligence makes many tasks relevant for such substitution as qualification and knowledge may not be not a problem for artificial brain that is permanently online and able to perform complex calculations and analyses much quicker than a human. It may make the problem of redundant workforce become acute fairly quickly.

It would seem that resolution of problems requiring non-standard approach or solution (potential innovation) might oblige the executive in the hierarchical structure to select a subordinate with maximum creativity and ignore the controllability factor. However, in this case the executive will not be able to control the new employee and prevent non-compliance or incorrect or untimely execution of the task that may reduce the pecuniary and non-pecuniary benefits of the manager and threaten his/her positions within the hierarchy. Therefore, in the real world, hierarchical manager also seeks to ensure the maximization of Di, but he is bound by the need to complete the creative task. Thus,

(5) Ci fixed at a minimally acceptable level.

(6) Qi is fixed at a minimally acceptable level.

(7) Di tends to max.

In the case of a creative task the hierarchy also seeks to ensure control over the employee. The conditions of our model will be satisfied with an employee who is the most controllable with initially pre-set degree of creativity and qualification. This leads to lower ranking of more creative but less controllable potential employees and exclusion from the competition of highly creative employees with low controllability together with employees with inferior creativity. 
Our model gives valuable insights into the paradigm of closed innovation that is built around the assumption of full control of the organization over innovation creation and development that is connected to the control over key personnel.

However, in the ultimate hierarchy it is possible to maximize Di using external, exogenous factors in a unified manner for all potential employees and thus obtain employees' ranking according to the creativity level as in ideal world. This may be achieved through "sharashka" described by Solzhenitsyn (1968) in his "The First Circle". "Sharashka" is a secret research and development laboratory in the Soviet Gulag labor camp system. Many famous scientists and researchers in Stalin's USSR passed through detention and "sharashka" (Ings 2016). Since control by the hierarchy reaches its maximum in prison or prisonlike environment and $\mathrm{Di}$ is set at maximum, then it is possible to use any employee, including those with Cmax or close to Cmax and Qmax or close to Qmax.

With controllability being the major factor for recruiting and, consequently, survival in the world dominated by hierarchies it is evident that selection patterns applied in hierarchies may have consequences that exceed by far the scope of hierarchical organizations and have direct impact on the human survival and social selection as a whole. In this connection it is interesting to note that according to biologists human brain has significantly shrunk during the last 20 000 years. The reasons for this may be related to the research of Russian geneticist Dmitry Belyaev (1979) who studied the breeding and domestication of silver foxes with the strong selection pressure for tamability. This unique research showed that the size of foxes' brain after 35 generations of experiments has become significantly smaller. Based on this and other researches some social psychologists argue that increase of exogenous control may be responsible for human brain "domestication" (Hood, 2014), shrinking of the human brain and growing role of the social in our lives. Thus, the hierarchy recruiting and selection model may have far larger impact than just innovation in the firm. It's also worth noting that hierarchy as organizational model migrated from professional military circles that had a relatively limited impact on the population, as the army service was not universal until late 19 century and the women were not recruited, to general civil use with the development of manufacturing, modern corporation and bureaucracy that have a practically universal application around the globe. This may mean that we witness for the last 150 years the consequences of hierarchy playing a major role in the human brain changes both at biological and psychological levels.

\section{Case study of model testing in hierarchical organization}

In order to test the model empirically and better understand the recruitment patterns in large organizations and their influence on the level of innovation within hierarchies we have chosen to use a two stage process.

First, we have identified the traditional hierarchical large organization that has low acceptance for innovations and largely relies on outsourced innovative solutions. In our case we have chosen Russian state-owned corporation that 
ignored such major development in its field of competence as shale gas production and fracking technologies.

Second, we have undertaken a series of semi-structured interviews with senior and mid-senior management (level of head or deputy head of department) of the organization. In the interviews we have asked the respondents to describe their typical reaction or anticipated typical reactions of their colleagues to standard situations that may arise in relation to recruitment of new employees or external or internal stresses. We have also explored pairs of different characteristics of potential employees (for example, "loyal" versus "creative") in order to establish rankings of preferred characteristics and compare the reactions to different sets of skills and qualities of potential recruit.

In the overwhelming majority of interviews (19 of 24) our counterparts underscored loyalty as key characteristic for recruitment. As one of respondents put it, "it does not matter what the person knows, we can teach him what he does not know but we do not have either ability or time to teach him loyalty". Our interviewees expressed certitude that the candidate should meet some basic requirements but these may be fairly basic and even these basic requirements can sometimes be ignored. A good sign of potential loyalty is a personal introduction or recommendation from a friend or a reliable colleague. Another useful indicator is the number of years spent in the previous organization or department. The recommendations of former colleagues, managers or subordinates are not highly appreciated. According to one of the interviewees "as soon as the person is out of job he is as good as dead for his former colleagues. De mortuis aut bene aut nihil. That's why I personally never say anything compromising about former colleagues. Besides, you never know under what circumstances you might meet in the future so it's worth abstaining from any conflict situation. And that's the reason I do not trust recommendations of people whom I personally do not know well enough."

Table 1. Necessary characteristics of potential employee

$$
\text { Loyalty/Controllability Qualification/Experience Creativity }
$$

\begin{tabular}{lccc}
\hline Primary requirement, in \# & 19 & 5 & 0 \\
of responses & 4 & 17 & 3 \\
Secondary requirement, in & &
\end{tabular}

Source: Research interviews, author's calculations

Similarly, candidate's creativity or super-intelligence or extra qualification is apprehended as a threat to status quo and a potential threat to personal wellbeing as "it is difficult to foresee what he (the candidate) might do". At the same time some of the interviewees expressed concern that such a candidate might naturally become a candidate for the manager's own position and thus a direct threat to the prospects and well-being of the executive. 
However, there is an interesting twist to that. As formal recruitment process goes through the $\mathrm{HR}$ department (informal procedure also involves $\mathrm{HR}$ department but in it HR usually plays just administrative and secretarial role coordinating candidates provided by the manager of the functional department), three interviewees from HR department stated that they always try to select the best external (not sourced by functional department) candidates based on job requirements submitted to $\mathrm{HR}$ service by relevant departments and the candidates they select are quite knowledgeable and creative. However, they rarely get any further than initial HR interview. On the other hand, when asked about recruitment practices for their own department the same interviewees have indicated that team spirit and person's psychological fit with them and colleagues is more important than the candidate's knowledge, experience or innovative approaches.

To our surprise a rare opportunity for a person with above-average knowledge or innovation skills to be hired opens in emergency or highly specialized situations. In order to fill highly specific position under time pressure managers (17 of 24 respondents) express readiness to hire the person who may not be completely loyal. Nevertheless, all of them express doubts about his or her longterm and even short-term survival in organization especially after initial crisis is over. They also underscore necessity to allocate additional resources and efforts to control such employee and 9 out of 24 are ready to part with him or her at the first available opportunity.

The results of our case study demonstrate that in regular situations hierarchy has a tendency to recruit mainly loyal employees whereas emergences and crises may open opportunities for more innovative types.

\section{Innovators and counter hierarchical approach}

As we have seen innovations and innovators encounter significant difficulties in civil hierarchy. That makes even more striking the alternative experience of innovation breakthroughs illustrated by the history of the Defense Advanced Research Projects Agency (DARPA). Over the past 50 years, DARPA succeeded in an unprecedented series of historic technological innovations. These innovations include Internet, composite and additive materials, GPS satellites, stealth technologies, drones, telesurgery, microelectromechanical systems (MEMS) etc. Although the US Defense Department is the principal customer of DARPA, DARPA's research played a central role in creating a number of new industries with billions of dollars' turnover. It means that within military chain of command where hierarchic principles are applied universally there may exist an innovation agency where innovators get what they deserve. Even more impressive than the long list of DARPA's achievements are a small organizational structure and a relatively limited budget. Its programs, on average, last no more than three to five years. About 100 fixed-term managers of technical programs and contracted contractors-individual consultants or teams hired from universities, companies, laboratories, government partner organizations and non-profit organizations, are working on projects. The support staff consists of 140 people - specialists in finance, contracting, personnel, security and law. The annual budget for about 
200 programs, which are maintained at any given time, is about $\$ 3$ billion. DARPA's approach to providing breakthrough innovations proved its viability and may represent an attractive alternative to traditional models used in large organizations (Greenwald, 2013).

However, the detailed investigation of DARPA's success shows that it is based on countercultural and counter hierarchical approach. The agency attracts worldclass experts from industry and science to work on projects for a relatively short period of time (Dugan and Gabriel, 2013). The temporary technical leader, who has reached a high level in his/her field of research and possesses exceptional leadership skills, organizes and leads the members of the project team. Projects are not open-focus research programs. Their intensity, clear focus and limited time frames make them attractive to people of the highest caliber, and the nature of the problem being solved ensures the highest level of cooperation. In other words, projects attract great people to solve great problems together with other great people. However, these people do not engage in hierarchical structures. By statute, DARPA is fully autonomous in the selection and implementation of projects. Such independence allows the organization to move quickly and take high risks. It also provides DARPA with an opportunity to attract the best and brightest representatives of the scientific and technical elite. The agency was established in 1958, shortly after the Soviet Union launched into space the first artificial earth satellite, which caused a national crisis in the United States. Concern about the fact that the USSR has achieved technological superiority, has led to the formation of an agency. The mission of DARPA at its foundation was formulated simply: "To prevent and create strategic surprises."

DARPA model gives exceptional leaders an environment in which they can realize what others may consider a crazy idea, a challenge to the whole industry, or act as a catalyst for the creation of a new industry. From a practical point of view, the high-risk efforts of a diverse set of world-class specialists can only be maintained for a limited period of time. One of the reasons is intensity. Another is that both the problems and the novelty of the scientific advances needed to solve them are, in essence, perishable goods. If the desired qualities cannot be created within a limited time frame, it is likely that someone else will be able to create them or come up with another solution. The third reason is the nature of innovation culture within DARPA as DARPA offers its innovations to the larger market, applying in practice the model of open innovations.

In DARPA people who do not normally interact cooperate and inform each other. A scientist exploring a new field often has so many opportunities for research that it is difficult for him/her to choose among them and concentrate. On the other hand, people working in the industry, trying to create new innovations, face the need to do something new, but some scientific aspects block them. Within the team, various specialists work together, industry representatives unite and discuss their problems with scientists who offer possible solutions. Such interaction can occur, bypassing the boundaries of disciplines. This dynamics create an extremely creative, fast, iterative cycle and provides breakthroughs in time that seems incredibly short.

The project manager organizes all efforts. He or she determines which parts of the work are necessary to obtain the result, conducts a call for proposals and hires organizations to carry out the work, and already these organizations collect the subcontractors that they require. Project managers who can successfully 
manage DARPA's projects possess the skills of the best general directors of scientific and engineering start-ups. Some project managers have previously held similar positions. Others come from academia, government laboratories, corporations and non-profit organizations. They must have deep technical or scientific knowledge, be ready to accept risks and be leaders capable of creating a strategic vision that would inspire the whole team.

Project managers monitor the performance of performers, manage technical details and make all important decisions. They own budgets, contracts, performance issues, public appearances and reports, as well as relationships with clients. Many, but not all, project managers have academic degrees. As a rule, they are about 40 years old, the last scientific degree was received by them five or ten years ago, and by the time of their appointment important achievements have already been made (an innovation product or technology was brought to the market, successful management of the university research center was realized, the company was launched). Trust is important. These leaders, who are in the middle of a career, can hire people who are older and more experienced; they must be able to act independently.

Interestingly, project managers rarely have an MBA. A set of skills acquired in a business school consists in identifying market opportunities, writing plans, and then implementing them in good faith. In contrast, DARPA is more focused on managing flows - creating directions, rescheduling, changing tactics and moving employees. Such leaders are sought through DARPA's networks, current and former DARPA program managers, directors and executors. For three years, 75 program managers out of 100 are replaced in connection with the end of some projects and the beginning of others. This confirms once more counter hierarchical principles of DARPA's work and the success that can be achieved when hierarchy is out of the way of innovators. Work for DARPA has a number of attractive features. It is a service to the nation, an honor to be invited to work in an elite organization with a legendary history and an opportunity to do something amazing, often countercultural.

\section{Model implications for filling positions in hierarchy and crises of hierarchy}

Based on the proposed model, it appears that each succeeding higher level of the hierarchy, on the one hand, is under stricter control from above, and on the other, the higher is the employee's controllability the better chance he/she has to ascend from lower levels. At the same time, people who are not controllable by higher levels in hierarchy tend to be evicted from it. Thus, the more levels in the hierarchy, the stricter employees are controlled at the top of the pyramid.

Perhaps it would be correct to assume that people in general can be divided into categories according to the controllability, and personnel with a high degree of controllability may be better able to achieve success within the hierarchy, and the employees with a low degree of controllability are more able to fulfill themselves in the market. According to Uusi-Kakkuri et al. (2016) young innovators are less comfortable with active management than their peers and 
thus they may consciously avoid hierarchical organizations where the management exercises extensive control over the employees.

What happens at the highest level then? Historically, within the hierarchy the decision on future heir's access to the highest place is taken either by a retiring leader or a group of senior managers, who, in either case in their decision follow the need to ensure their own control over the newly appointed leader. Thus, the chief executive is chosen based on the same principles (controllability, skills, creativity, with controllability playing the most important role). This is the reason that in the established hierarchies, closest to the ideal model, the new leader appears to be either the most controllable manager, or the manager, who controls the most disciplined part of the hierarchy, but not the most creative or skilled. This is especially true for managerial hierarchies in which the owners' control (shareholders or voters) is essentially weak whereas the competition between potential or real managers is high. Consider, for example, the promotion of Stalin (and not Trotsky) after the death of Lenin in Soviet Russia or the election of the pope of Catholic Christians or patriarch of the Eastern Orthodox Christians.

Due to its way of recruiting hierarchy repels most people with a high degree of creativity and independence. However, among such people there are significantly more bearers and promoters of innovative ideas. This leads to the fact that, in contradiction to Schumpeter's (Ibid.) hypothesis radical innovations are impossible within the hierarchy. On the contrary, well-established hierarchy may lead to a simplification of activities and slowing innovation development process. This confirms Weber's (1978) idea of dehumanizing iron cage of bureaucracy that is another instance of hierarchy. Over time this may be the cause of higher production costs in the hierarchy compared to the market. Hierarchy's internal structure, while the number of hierarchy levels may increase or decrease, tends to lag behind changes in the external environment and to become vulnerable to external shocks, although the sensitivity to these shocks may be due to the functioning of the hierarchy itself.

Some may argue that knowledge organizations may be different in this respect from more traditional organizations. Thus, Amar and Hlupic (2016) suggest that knowledge organization leaders, instead of using their own authority, may allow everyone related to the task the opportunity to lead. However, such shift in leadership paradigm will have an impact on the behavior of all personnel, and will gradually bring a change in the social behavior norms. Similarly, Steiber and Alange (2013) consider Google's organization as a dynamic and open corporate system for continuous innovation that involves the whole organization. This open innovation corporate system is maintained and supported through significant efforts of top management and board. Nevertheless, researchers underscore the importance of such factors as corporate culture and correct selection of individuals in order to sustain continuous innovation over time.

To improve its efficiency and catch up with competitors and/or the market the hierarchy needs to be renewed, that is, people with high creativity should ascend to positions of responsibility. Such people may have been expelled or put to reserve at the lower levels of the hierarchy due to a lower controllability.

How does the renewal take place in the most traditional military hierarchy? Victory does not lead to renewal whereas in case of defeat the head or the upper part of the hierarchy is removed. Subsequently promotion of the most 
distinguished officers goes up. These are the servicemen, who showed themselves in the best way. This promotion functions without taking into account the degree of controllability of these officers, since the survival of the hierarchy of the organization (or nation) in its entirety is under threat. A classic example of this renewal is the promotion of Napoleon: from a modest artillery officer with questionable, practically foreign origins to General and emperor of France (de Villepin, 2007).

Similarly, in civil hierarchical organizations crisis is a way to renew the hierarchy. The firm's crisis manifests itself in different ways: a decrease in sales, losses, the appearance of raiders, but the result is the same: the choice between a renewal of the hierarchy in order to integrate management and technology innovations, adapt to changing market or destruction of the organization as a whole. Such examples are most vivid in technologically and scientifically advanced sectors of economy. Consequently, for example, it is not surprising that innovation tends to occur in smaller pharma companies, which are then bought by larger pharma companies that do have a comparative advantage in marketing, sales and other more traditional activities.

Thus, in order to adopt and implement innovations a hierarchy requires internal or external shocks. On the one hand, due to its own logic of development hierarchy ignores changes in the environment and the need for innovation and transformation till the last moment and thus contributes to the accumulation of the necessary changes to the critical level, when it threatens the existence of hierarchy. In this situation, the hierarchy brings up new people with a high degree of creativity and skill, but less controlled. An excellent illustration of this is the demise of the Soviet Union, where the nomenclature, knowing the problems of the USSR and its lack of competitiveness, after the death of Brezhnev put forward traditional, well-controlled representatives of the hierarchy for the position of the country leader. However, after realizing the scale of the threat the highest authority was handed to poorly controlled but creative Gorbachev. The history of Apple with return of Steve Jobs or Chrysler under Yacocca may be good examples from corporate life.

On the other hand, it is possible to say that to a certain degree hierarchy itself generates these shocks. Any army (perfect hierarchy) is exaggerating the importance and inevitability of armed conflict to ensure its own financing and development. Similarly, any hierarchical organization is interested in the research and exaggeration of threats to mobilize and renew the personnel and grow in size.

However, such expansion beyond physical limitations has a permanent germ of its own self destruction in the form itself of hierarchical organization. The hierarchy seems to be unable to innovate or reform itself without the pressure of the imminent crisis. Thus, the renovation of hierarchy may take place only in crisis mode or in dire circumstances where the survival of the hierarchy depends on the innovation. When the environment undergoes drastic changes, it is necessary to make changes to the navigation charts and change the captain or even the whole crew. New business models are reshaping the competitive environment and the boundaries of the industries are changing. In these conditions such traditional tools of strategic analysis as the five forces of Michael Porter, created for a more stable world, not only lose their relevance, but are also actively misleading. In today's economy, companies can start their business and reach a huge scale with incredible speed, using quite limited capital. Costs easily 
move between industries. Uberization shows that business can develop and thrive using the stock of other businesses or individuals instead of immobilizing capital and liquidity in own reserves. Entrepreneurs and start-ups often have advantages over large incumbent enterprises. The life cycle of companies is shrinking with time for decision making requiring fast and creative approaches.

Over the years, economists have used a two-stage model of labor productivity, in which developed countries have been constantly increasing productivity, and developing countries have been trying to catch up with the developed ones. Some of the developing countries like Asian tigers managed to build their manufacturing and research facilities in international value chains and secure their place among th developed nations. Nevertheless, the majority of developing countries are still less productive than the developed countries. However, those countries that use the capital-intensive model of catching-up development find that this model is becoming increasingly difficult to maintain, as their economies become more consumer-oriented and service-oriented. On the other hand, innovation and mobile technology should provide a platform for accelerating development, as in Africa, for example, where already 15 percent of bank transactions go via mobile banking (compared to 5 percent in developed countries), or in China, where Alibaba led the online consumer market development to an unprecedented reach and scale.

Instead of considering the national market as consisting of 4-5 value segments, as it was before, today it is necessary to understand the market in which the offers of the same product can differ depending on the location within the country, as well as on the distribution channel used and the demographic segment targeted. The global process of population aging and increase in income inequality requires more and more diverse approaches to the consumer. Accordingly, a highly flexible approach is needed, both global and local.

The convergence of IT and the materials sciences leads to the innovations that change when, where and how humanity uses natural resources. The combination of information technology, material sciences at the nano level and biology with industrial technology provides a significant increase in labor productivity and resource efficiency. Such improvements represent a unique opportunity to create value and will be the key to achieving economic growth by increasing productivity in developing countries. The implementation of these opportunities requires new management approaches, such as substitution (the replacement of costly, inconvenient or scarce materials with less scarce, cheaper and high-performance substitutes), optimization (large-scale use of software in resource-intensive industries to improve the production process and use of limited resources) and virtualization (moving processes from the physical world to the virtual world).

Innovation also may reduce entry barriers, making the established boundaries between industries disappear. At the same time, the very nature of innovative assets causes the disruption of supply chains, creating opportunities for focused and dynamic competitors. New market participants are rapidly increasing the scale of their activities, and at a lower price than traditional players. Simultaneously, a rapid increase in revenues, returns and yields is possible, as more and more customers join new networks.

All these developments represent a significant threat to hierarchical incumbent organizations in different sectors and industries and when these 
threats are timely and correctly identified this may lead to the hierarchy crisis and, consequently, to hierarchy renovation or destruction under the onslaught of more innovative competitors. However, the destruction of the largest companies under the influence of disruptive innovations can represent a serious social, economic and political problem and even a catastrophe for the nation, local communities and society. Crises are the imminent features of hierarchical organization and may be not an exogenous factor but an endogenous one taking into account the way how the innovators who could have provided for more evolutionary development are recruited and welcome within these large organizations.

\section{Conclusion}

The proposed model of employee selection within hierarchies offers framework that shows that bearers of innovations violate stability of hierarchies and may not be able to effectively carry out their activities within them. Therefore, innovation activity together with its bearers is taken outside the hierarchical structures and into the market; this leads to the emergence and development of open innovations, where innovations are publicly exchanged and traded between organizations as well as the owners of innovations. Possibly, the main path for integrating innovations in the hierarchy becomes mergers and acquisitions of other companies, followed by the creation of new hierarchies on the basis of merged entity. Technological advances lead to a continuous series of crises of hierarchical structures and their renovation and/or gradual displacement by markets and other types of cooperation not based on subordination. All this may be the cause of quick changes at the top of corporate world. As evidenced by Hannah (1998) just 20 companies of initial list of 100 world largest companies conserved their place among top 100 in the period from 1912 to 1995.

Possible further research venues may include discussion of impact of crisis on innovation and hierarchies' personnel at different levels, empirical studies of hierarchical and non-hierarchical organizations, possible re-organizing of the recruitment processes within hierarchies with candidates being selected by external authority, use of collaborative practices and other application of these principles to large hierarchical organizations with the view of better preparation for imminent crises and disruptive innovation that may impact the firms' size and market positions as well as the relationship between controllability and creativity. More general research issues may tackle the impact of hierarchies on human development and social structures and possible implications for the social, biological and psychological aspects of the humankind.

Companies that have mastered the skill of innovation, such as Apple, BMW, Google, Procter \& Gamble, Motorola, have gone much further than simple research and development to ensure that innovation becomes an integral part of their organization and value chain. This approach provided these companies with a long-term competitive advantage. The need to learn from innovative leaders is obvious. Innovation is a science, not an art, and it is the scientific approach that makes it possible to create commercially viable ideas. 
One of the prominent features of innovative leaders companies are significant investments in comparison with their peers or competitors in the initial stages of the innovation process (development of innovative strategy, generation of ideas, screening of ideas).

In the development of innovation strategy, the key person is the personality of the manager/leader and his/her commitment to innovation. An innovative manager contributes to the development of an effective innovation strategy, which should provide strategic growth through innovation. A successful innovation strategy includes clear operational goals and timelines, adequate budgets and an understanding of projected revenues. Innovative strategy forms the basis for a corporate culture focused on innovation. We see that personnel selection plays the leading role in determining the corporate innovation prospects.

Generating ideas through open innovation may also become an important factor in the success of companies. For the best innovative companies almost half of the innovations are the result of ideas that have emerged outside these companies. Extensive programs of interaction with partners allow to attract and coordinate the innovation process, providing the necessary openness and efficiency. Interestingly, a company like Procter \& Gamble supports a special innovative training complex, which consists of rooms for brainstorming with various simulators. The company has built mock-ups retail stores in order to conduct experiments with the organization of store space, the layout of goods and advertising. These stores are used to hold focus groups to improve understanding of consumers' behavior and imitate shopping experience. Commercial facilities also include warehouses in order to determine the effects on the supply chain.

To screen ideas, it is necessary to use a number of criteria - financial indicators, technological trends, simplicity of production and alignment to corporate strategy, product development, social and economic trends. Best practices involve the simultaneous pursuit of both incremental and radical innovation at the same time. Innovative companies invest heavily in the initial stage, making larger bets, but more carefully selecting projects at subsequent stages. In all these enterprises personnel and its creative abilities and possibilities of application of innovative potential play a crucial role.

The organizational structure for success must be focused on innovation. It is not rare that a separate research and development department is created, focusing exclusively on interaction with partners. We compare this experience with DARPA as it is also placed outside the traditional corporate hierarchy in order to obtain better results. It is necessary to determine which specialists of the department will conduct the screening of innovative ideas and how the remuneration will be distributed based on the results of innovation. Innovative companies should provide a free flow of ideas and people within the company, simplicity and structured interaction both within the company and with the external environment. This ensures the creation of a corporate innovation culture. Companies lagging behind in adopting such innovative methods risk losing in competition and being stuck in the role of observers of the better innovative peers and competitors.

Ability to innovate in business will increasingly determine which companies create and which ones lose value. These shifts occur in the context of the evolution of industries that are not monolithic, but can follow a well-known scheme: as the new trends emerge, new players appear that destroy traditional 
markets and views, and their innovative products and services attract early followers; advanced industry players begin to adapt to these changes, speeding up the pace of customer acceptance of changes; the level of innovation in the industry - not only among companies, but, and perhaps more importantly, among consumers - reaches the turning point. In the end, what was once radical innovation becomes common, and players who have missed the innovation run huge risk of failing while those who have successfully developed new abilities, are turning into powerful players.

This ability to innovate is closely related to the organizations' abilities to attract, support and hold the innovative personnel avoiding the pits due to the very nature of hierarchical organization.

\section{Acknowledgements}

I would like to thank Professor Jean-Jacques Rosa for his thoughtful comments and encouraging support in preparation of this paper as well as the participants of seminars in Moscow.

\section{References:}

Alchian, Armen A., and Harold Demsetz (1972), Production, Information Costs, and Economic Organization, The American Economic Review, Vol. 62, No. 5 (Dec., 1972), pp. 777-795.

Amar A.D., and Vlatka Hlupic (2016), Leadership for knowledge organizations, European Journal of Innovation Management, Vol. 19 Issue: 2, pp.239-260, https://doi.org/10.1108/EJIM-12-20140120.

Baron, James N., Michael T. Hannan, and Diane Burton (1999), Building the Iron Cage: Determinants of Managerial Intensity in the Early Years of Organizations, American Sociological Review, Vol. 64, No. 4 (Aug., 1999), pp. 527-547.

Belyaev, Dmitry K. (1979), Destablizing selection as a factor in domestication, Journal of Heredity, 70 (5), 301-308.

Bower, Joseph L., and Clayton M. Christensen (1995), Disruptive Technologies: Catching the Wave, Harvard Business Review, 73, no. 1 (January-February 1995): pp. 43-53.

Breton, Albert, and Ronald Wintrobe (1982), The logic of bureaucratic conduct, Cambridge University Press, Cambridge.

Bush, Vannevar (1945), As We May Think, The Atlantic Monthly. July 1945, pp. 112-124.

Bush, Vannevar (1945), Science, the Endless Frontier, National Science Foundation, Washington, DC.

Chesbrough, Henry (2003), Open Innovation: The New Imperative for Creating and Profiting from Technology, Cambridge, MA, Harvard Business School Press.

Christensen, Clayton M. (1997), The Innovator's Dilemma: When New Technologies Cause Great Firms to Fail, Harvard Business Review Press.

Christensen, Clayton M. (2003), The Innovator's Solution: Creating and Sustaining Successful Growth, Harvard Business School Press.

Ciborra, Claudio U. (1993), Teams, Markets and Systems, Cambridge: Cambridge University Press.

Clemons, Eric K., Sarah P. Reddi, and Michael Row (1993), The Impact of Information Technology on the Organization of Economic Activity: The" Move to the Middle" Hypothesis, Journal of Management Information Systems 10(2), pp. 9-35.

Coase, Ronald (1937), The Nature of the Firm, Economica, Blackwell Publishing, 4 (16): 386-405. doi:10.1111/j.1468-0335.1937.tb00002.x

Coase, Ronald (1960), The Problem of Social Cost, Journal of Law and Economics, Vol. 3 (Oct., 1960), pp. 1-44.

Coetzee, Daniel and Lee W. Eysturlid (2013), Philosophers of War, The Evolution of History's Greatest Military Thinkers, Praeger. 
Constantiou, Ioanna and Jannis Kallinikos (2015), New games, new rules: Big data and the changing context of strategy, Journal of Information Technology 30(1), pp. 44-57 March 2015 doi: $10.1057 /$ jit.2014.17

Cordella, Antonio (2006), Transaction costs and information systems: does IT add up? Journal of Information Technology, 21 (3), pp. 195-202.

d'Este, Pablo, Surya Mahdi, Andy Neely, and Francesco Rentocchini (2012), Inventors and entrepreneurs in academia: What types of skills and experience matter? Technovation, 32, 9-10, pp. 293- 303.

Dahlandera, L., and D. Gannb, M. (2010), How open is innovation? Research Policy, 39, pp. 699-709.

de Villepin, Dominique (2007), Le soleil noir de la puissance, 1796-1807, Perrin, Paris.

Dugan, Regina, and Kaigham Gabriel (2013), «Special Forces» Innovation: How DARPA attacks problems, Harvard Business Review, October 2013.

Freeman, Christopher and Bengt-Ake Lundvall (1988), Small Nations Facing the Technological Revolution, London, UK, Pinter Publishers.

Gans, Joshua (2016), The Disruption Dilemma, MIT Press.

Greenwald, Ted (2013), Secrets of Darpa's Innovation Machine, Forbes, February 13, 2013.

Hannah, Leslie (1998), Survival and Size Mobility among the World's Largest 100 Industrial Corporations, 1912-1995, The American Economic Review Vol. 88, No. 2, Papers and Proceedings of the Hundred and Tenth Annual Meeting of the American Economic Association (May, 1998), pp. $62-65$.

Hood, Bruce (2014), The Domesticated Brain, Penguin Books, London, UK.

Ings, Simon (2016), Stalin and the Scientists: A History of Triumph and Tragedy 1905-1953, Faber \& Faber.

Kline, Stephen and Nathan Rosenberg (1986), An overview of innovation, In: Landau, R., Rosenberg, N. (eds.), The Positive Sum Strategy: Harnessing Technology for Economic Growth, Washington, DC, National Academy Press, pp. 275-305.

Malone, Thomas W., Joanne Yates, and Robert I. Benjamin (1987) Electronic Markets and Electronic Hierarchies: Effects of information technology on market structure and corporate strategies, Communications of the ACM 30: 484-497.

Marx, Karl (1959), Economic and Philosophic Manuscripts of 1844, Progress Publishers, Moscow.

Putnam, Robert (1993), Making democracy work: civic tradition in modern Italy, Princeton University Press, Princeton.

Rifkin, Jeremy (2011), The Third Industrial Revolution: How Lateral Power is Transforming Energy, the Economy, and the World, Palgrave MacMillan.

Rogers, Nicholas (2008), The Press Gang. Naval Impressment and its opponents in Georgian Britain, Hambledon Continuum.

Schmookler, Jacob (1966), Invention and Economic Growth, Harvard University Press, Cambridge, MA.

Schumpeter, Joseph A. (1934), The Theory of Economic Development, Harper \& Row, New York.

Schumpeter, Joseph A. (1942), Capitalism, Socialism and Democracy, Harper \& Row, New York.

Solzhenitsyn, Aleksandr (1968), The First Circle, Collins, Harvill Press.

Steiber, Annika, and Sverker Alaenge (2013), A corporate system for continuous innovation: the case of Google Inc., European Journal of Innovation Management, Vol. 16 Issue: 2, pp.243-264, https://doi.org/10.1108/14601061311324566.

Uusi-Kakkuri, Piia, Tiina Brandt, and Susanna Kultalahti (2016), Transformational leadership in leading young innovators - a subordinate's perspective, European Journal of Innovation Management, Vol. 19 Issue: 4, pp.547-567, https://doi.org/10.1108/EJIM-12-2014-0118

Weber, Max (1978), Economy and Society: An Outline of Interpretive Sociology, University of California Press.

Williamson, Oliver E. (1985), The Economic Institutions of Capitalism: Firms, Markets, Relational Contracting, Collier Macmillan, New York, London: Free Press.

Wojtczuk-Turek Agnieszka, and Dariusz Turek (2015), Innovative behaviour in the workplace: The role of HR flexibility, individual flexibility and psychological capital: the case of Poland, European Journal of Innovation Management, Vol. 18 Issue: 3, pp.397-419, https://doi.org/10.1108/EJIM-03-2014-0027 